\title{
Gamma knife surgery for pineal region tumors: an alternative strategy for negative pathology
}

Cirurgia com gamma knife como tratamento experimental para tumores da região da pineal: uma estratégia alternativa quando os dados anatomopatológicos são negativos

Peng Wang',2, Qing Mao', Wei Wang', Liang-Xue Zhou', Yan-Hui Liu'

\begin{abstract}
Objective: Pineal region tumors (PRTs) are uncommon, and treatments vary among neoplasm types. The authors report their experience with gamma knife surgery (GKS) as an initial treatment in a series of PRT patients with unclear pathological diagnoses. Method: Seventeen PRT patients with negative pathology who underwent GKS were retrospectively studied. Nine patients had further whole-brain and spinal cord radiotherapy and chemotherapy 6-9 months after GKS. Results: Sixteen of 17 cases were followed up over a mean of 33.3 months. The total response rate was $75 \%$, and the control rate was $81.3 \%$. No obvious neurological deficits or complications were attributable to GKS. Conclusion: The findings indicate that GKS may be an alternative strategy in selected PRT patients who have negative pathological diagnoses, and that good outcomes and quality of life can be obtained with few complications.
\end{abstract}

Keywords: gamma knife surgery, pineal region tumors, radiosurgery.

\section{RESUMO}

Tumores da região da pineal (TRP) são pouco frequentes e as propostas de tratamento são bastante variadas. Os autores relatam sua experiência em cirurgias com uso gamma knife (CGK) como tratamento experimental inicial em séries de TRP que não têm diagnóstico anatomopatológico ou nos quais o diagnóstico não ficou claro. Foram estudados retrospectivamente 17 pacientes com TRP nestas condições e que foram submetidos a CGK. Destes, 9 pacientes foram submetidos posteriormente a radioterapia de todo o encéfalo e medula espinhal entre 6 e 9 meses depois da CGK. Dezesseis dos 17 pacientes foram acompanhados por um período médio de 33,3 meses. A taxa total de resposta nos pacientes foi de 75\% e a taxa dos controles, 81,3\%. Não houve nenhum déficit neurológico evidente que pudesse ser atribuído à CGK. A CGK como tratamento experimental pode ser uma estratégia alternativa no grupo específico de pacientes com TRP em que não há diagnóstico anatomopatológico, podendo ser obtida uma boa qualidade de vida com poucas complicações para esse grupo de pacientes.

Palavras-chave: cirurgia com gamma knife, tumors da região da pineal, radiocirurgia.

Pineal region tumors (PRTs) account for $1-3 \%$ of all primary brain tumors ${ }^{1}$. They have very complex pathological types, including germ cell tumors, pineal parenchymal tumors, gliomas, meningiomas, ependymomas, lymphomas, neuronal tumors, and metastases ${ }^{2,3}$. Treatment strategies for these tumors vary, and many experts suggest that PRT management strategies depend on an accurate histologic diagnosis. Radiotherapy and chemotherapy are usually suggested for radiosensitive or malignant tumors, while surgical resections are recommended for benign tumors ${ }^{4-9}$.
However, it is not possible to obtain accurate pathological diagnoses in a subset of PRT patients, either because open biopsy (craniotomy) is high risk or because stereotactic biopsy carries a certain rate of diagnostic failure. Although sufficient specimen and total or partial tumor resection are options in open biopsy, the surgery is high risk and has a 5-20\% morbidity (major or minor) rate ${ }^{4-6}$, even with advancements in microsurgical techniques. In addition, the operation requires extensive technical skills and experience ${ }^{10}$. Stereotactic biopsy is less likely to result in mortality and morbidity, but

'Department of Neurosurgery, West China Hospital, Sichuan University, Chengdu, China;

2Department of Neurosurgery, The Fifth People's Hospital of Chengdu, Chengdu, China.

Correspondence: Yan-Hui Liu; Department of Neurosurgery, West China Hospital, Sichuan University, 37\# Guoxue Alley, Chengdu, 610041 China;

E-mail: liuyanhui9@gmail.com

Conflict of interest: There is no conflict of interest to declare.

Received 28 June 2013, received in final form 20 October 2013. Accepted 28 October 2013. 
yields only a small pathology specimen, which can be challenging for even experienced neuropathologists ${ }^{11}$. Moreover, for some tumors with a combination of benign and malignant components, it is hard to make an accurate pathological diagnosis with a limited amount of biopsy material ${ }^{2,3}$. There is also a risk of hemorrhage because of the nature of tumor vasculature and the density of vascular structures in the pineal region ${ }^{12}$. Recently, neuroendoscopy has been used in the initial management of PRTs, as this minimally invasive technique can obtain more tumor tissue during biopsy. However, $6-25 \%$ of patients had a negative pathological diagnosis ${ }^{7-9}$, and some experts still argue that this procedure provides limited tissue samples ${ }^{13}$.

In patients with a negative pathological diagnosis, radiotherapy could be a viable alternative treatment because some PRTs are radiosensitive ${ }^{14}$. This is especially true in Asia ${ }^{15,16}$, where radiosensitive PRTs account for a higher percentage $^{17,18}$. Kanamori and colleagues ${ }^{16}$ showed that 32 of 41 PRT patients treated with neoadjuvant chemotherapy and radiation therapy without histological verification achieved an excellent response.
Gamma knife surgery (GKS) is a stereotactic radiation treatment with better safety and fewer associated complications; it avoids adjacent brain tissues but delivers a high dose of radiation to the target lesion. Here, we report our experience using GKS for pathology-negative PRT patients.

\section{METHOD}

We retrospectively reviewed data from 17 PRTs patients treated with GKS who had no or unclear pathological diagnoses in our department from January 2005 to December 2009 (Table 1). The mean age of the patients was 25.5 years (12-65 years), and the male:female ratio was 15:2. All patients had preoperative three-dimensional cranial magnetic resonance imaging (MRI) and underwent laboratory tests for the tumor markers alpha fetoprotein (AFP) and beta chorionic gonadotrophin $(\beta-H C G)$. The average tumor diameter was $2.20 \mathrm{~cm}$ (range, $1.1-3.6 \mathrm{~cm}$ ), and $88.2 \%$ of tumors were $<3 \mathrm{~cm}$.

A Leksell stereotactic frame (Elekta Instruments $A B$, Stockholm, Sweden) was used for all patients, and images

Table 1. Patient summary*.

\begin{tabular}{|c|c|c|c|c|c|c|c|c|c|}
\hline Case No. & $\begin{array}{l}\text { Age, } \\
\text { sex }\end{array}$ & Treatment & $\begin{array}{c}\text { AFP, } \\
\beta-\mathrm{HCG}^{+}\end{array}$ & $\begin{array}{c}\text { Mean } \\
\text { diameter }\end{array}$ & $\begin{array}{l}\text { Marginal } \\
\text { dose }\end{array}$ & $\begin{array}{l}\text { Isodose } \\
\text { line }\end{array}$ & $\begin{array}{l}\text { Duration of } \\
\text { clinical FU }\end{array}$ & Response & $\begin{array}{c}\text { Complications/ } \\
\text { or death }\end{array}$ \\
\hline 1 & $27, \mathrm{M}$ & $\begin{array}{c}\text { VPS, GKS, } \\
\text { Chemo, WBSRT }\end{array}$ & $(-),(-)$ & $2.1 \mathrm{~cm}$ & 13 Gy & $50 \%$ & 56 mos & CR at 56 mos & None \\
\hline 2 & $16, \mathrm{M}$ & $\begin{array}{c}\text { VPS, GKS, } \\
\text { Chemo, WBSRT }\end{array}$ & $(-),(+)$ & $1.8 \mathrm{~cm}$ & 13 Gy & $50 \%$ & 30 mos & PR at 30 mos & None \\
\hline 3 & $12, \mathrm{M}$ & $\begin{array}{c}\text { VPS, GKS, } \\
\text { Chemo, WBSRT }\end{array}$ & $(-),(-)$ & $1.1 \mathrm{~cm}$ & 13 Gy & $50 \%$ & $61 \mathrm{mos}$ & $\mathrm{CR}$ at $61 \mathrm{mos}$ & None \\
\hline 4 & $21, \mathrm{M}$ & $\begin{array}{c}\text { VPS, GKS, } \\
\text { Chemo, WBSRT }\end{array}$ & $(-),(-)$ & $2.5 \mathrm{~cm}$ & 13 Gy & $50 \%$ & 25 mos & CR at 25 mos & None \\
\hline 5 & $20, \mathrm{M}$ & $\begin{array}{c}\text { VPS, GKS, } \\
\text { Chemo, WBSRT }\end{array}$ & $(-),(-)$ & $3.6 \mathrm{~cm}$ & 13 Gy & $45 \%$ & 64 mos & CR at 64 mos & None \\
\hline 6 & $16, \mathrm{M}$ & $\begin{array}{c}\text { VPS, GKS, } \\
\text { Chemo, WBSRT }\end{array}$ & $(-),(+)$ & $3.0 \mathrm{~cm}$ & 14 Gy & $45 \%$ & 15 mos & CR at 15 mos & None \\
\hline 7 & $31, \mathrm{M}$ & $\begin{array}{c}\text { VPS, GKS, } \\
\text { Chemo, WBSRT }\end{array}$ & $(-),(-)$ & $1.3 \mathrm{~cm}$ & 15 Gy & $50 \%$ & 60 mos & PR at 60 mos & None \\
\hline 8 & $18, M$ & $\begin{array}{c}\text { VPS, GKS, } \\
\text { Chemo, WBSRT }\end{array}$ & $(-),(-)$ & $1.6 \mathrm{~cm}$ & 14.5 Gy & $50 \%$ & 32 mos & CR at 32 mos & None \\
\hline 9 & $45, M$ & $\begin{array}{c}\text { GKS, Chemo, } \\
\text { WBSRT }\end{array}$ & $(-),(+)$ & $2.3 \mathrm{~cm}$ & 15 Gy & $50 \%$ & 9 mos & $\begin{array}{c}\text { PG at } 9 \text { mos } \\
\text { with VSS }\end{array}$ & $\begin{array}{c}\text { Died } 9 \text { mos after } \\
\text { GKS with ISS }\end{array}$ \\
\hline 10 & $65, F$ & VPS, GKS & $(-),(+)$ & $2.2 \mathrm{~cm}$ & 13 Gy & $50 \%$ & 43 mos & CR at 43 mos & None \\
\hline 11 & $13, \mathrm{M}$ & VPS, GKS & $(+),(-)$ & $2.4 \mathrm{~cm}$ & 13 Gy & $45 \%$ & 18 mos & PG at 18 mos & $\begin{array}{l}\text { Died } 18 \text { mos } \\
\text { after GKS }\end{array}$ \\
\hline 12 & $54, \mathrm{M}$ & VPS, GKS & $(-),(-)$ & $1.5 \mathrm{~cm}$ & 15 Gy & $50 \%$ & 16 mos & $\mathrm{CR}$ at 16 mos & None \\
\hline 13 & $34, \mathrm{M}$ & VPS, GKS & $(-),(-)$ & $1.6 \mathrm{~cm}$ & 14 Gy & $50 \%$ & 39 mos & CR at 39 mos & None \\
\hline 14 & $16, \mathrm{M}$ & VPS, GKS & $(+),(+)$ & $2.0 \mathrm{~cm}$ & 13 Gy & $50 \%$ & $2 \mathrm{mos}$ & $P G$ at 2 mos & $\begin{array}{c}\text { Died } 2 \text { mos after } \\
\text { GKS }\end{array}$ \\
\hline 15 & $18, M$ & GKS & $(+),(-)$ & $3.1 \mathrm{~cm}$ & 15 Gy & $50 \%$ & 35 mos & PR at 35 mos & None \\
\hline 16 & $13, M$ & GKS & $(-),(-)$ & $2.9 \mathrm{~cm}$ & 13 Gy & $45 \%$ & Lost & Lost & Lost \\
\hline 17 & $14, F$ & GKS & $(-),(+)$ & $2.4 \mathrm{~cm}$ & 14 Gy & $45 \%$ & $28 \mathrm{mos}$ & $\mathrm{NC}$ at $28 \mathrm{mos}$ & None \\
\hline
\end{tabular}

*GKS: gamma knife surgery;VPS:ventriculoperitoneal shunt;Chemo:chemotherapy;WBSRT: whole-brain and spinal cord radiotherapy;AFP: alpha fetoprotein; $\beta$-HCG: beta chorionic gonadotrophin; CR: complete response; PR: partial response; MR: minor response; NC: no change; PG: progression;VSS: ventricular and spinal spread; (-): negative; (+): positive.

† These two markers were tested in serum. 
for dose planning were obtained with a 1.5-Tesla superconducting magnetic resonance scanner (Siemens, Erlanger, Germany). Dose planning was carried out with Leksell Gamma Plan (Elekta Instruments $\mathrm{AB}$ ). The average marginal dose was 13.7 Gy (range, 12-15 Gy), and the average isodose line was $48.5 \%$ (range, 45-50\%). Ventriculoperitoneal shunt (VPS) was employed in patients with high intracranial pressure before GKS.

Clinical follow-up was by means of patient interview (face to face or telephone) and regular MRI examination every 3-6 months. The effects of GKS were evaluated based on clinical manifestations and radiological changes. MRI images were analyzed by two independent experienced radiologists according to a five-grade system, including complete response (CR), partial response (PR), minor response (MR), no change (NC), and progression (PG). Total response rate was defined as the percentages of $\mathrm{CR}$ and $\mathrm{PR}$, and control rate was the ratio of CR, PR, MR, and NC to total ${ }^{19}$. Karnofsky performance status (KPS) was assessed at admission and 6 months after GKS, and these two scores were compared to investigate the influence of GKS on quality of life.

\section{RESULTS}

Sixteen of 17 cases (94.1\%) were followed up over a mean of 33.3 months (range, 2-64 months), and one was lost to follow-up. Thirteen patients $(81.3 \%)$ were alive at the final follow-up (Table 1). CR was achieved in nine cases (56.3\%), PR in three cases (18.8\%), NC in one case (6.3\%), and PG in three cases $(18.8 \%)$; no patients showed MR. The total response rate was $75 \%$, and the control rate was $81.3 \%$ (Table 2). VPS was performed in 13 cases $(76.5 \%)$, as high intracranial pressure is the main symptom in patients with PRTs. No extranervous system metastases were found.

Serum testing for tumor markers (AFP and $\beta$-HCG) was negative in nine $(52.9 \%)$ cases, and either one or both were positive in eight cases (47.1\%). The relationship between tumor markers and response revealed that patients

Table 2. Tumor control*.

\begin{tabular}{lcc}
\hline Response & No. of cases & Percentage \\
\hline CR & 9 & $56.3 \%$ \\
PR & 3 & $18.8 \%$ \\
MR & 0 & $0.0 \%$ \\
NC & 1 & $6.3 \%$ \\
PG & 3 & $18.8 \%$ \\
Total response rate & 12 & $75.0 \%$ \\
Control rate & 13 & $81.3 \%$ \\
Total no. of cases & 16 & $100 \%$ \\
\hline${ }^{*}$ One case was excluded due to follow-up loss. \\
CR: complete response; PR: partial response; MR: minor response; NC: no \\
change; PG: progression.
\end{tabular}

with negative tumor markers had a tendency to achieve a CR regardless of whether they were treated with GKS plus WBSRT and chemotherapy or GKS only (Table 3).

Nine patients had further whole-brain and spinal cord radiotherapy (WBSRT) and chemotherapy (Chemo) 6-9 months after GKS. The whole brain and spinal cord were fractionally irradiated with doses from 3420-3600 cGy. The remaining seven patients (excluding the lost patient) did not undergo further treatment after GKS. There was no difference in survival $(\mathrm{p}=0.382)$ (Figure 1$)$ or control rate $(71.4 \%$ vs. $88.9 \%$, $\mathrm{p}=0.375$ ) (Figure 2) between the patients treated with GKS and those with GKS followed by WBSRT and Chemo.

Three patients died. One died 2 months after GKS due to disease progression. The second died 9 months after

Table 3. Tumor markers and response*.

\begin{tabular}{|c|c|c|c|c|}
\hline \multirow{3}{*}{ Reponses } & \multicolumn{4}{|c|}{ AFP/ $\beta-H C G$ in serum } \\
\hline & \multicolumn{2}{|c|}{ GKS, Chemo, WBSRT } & \multicolumn{2}{|r|}{ GKS } \\
\hline & $-/-$ & $+/-,-/+,+/+$ & $-/-$ & $+/-,-/+,+/+$ \\
\hline CR & 5 & 1 & 2 & 1 \\
\hline PR & 1 & 1 & 0 & 1 \\
\hline MR & 0 & 0 & 0 & 0 \\
\hline NC & 0 & 0 & 0 & 1 \\
\hline$P G$ & 0 & 1 & 0 & 2 \\
\hline No. of cases & 6 & 3 & 2 & 5 \\
\hline
\end{tabular}

* One case was excluded due to follow-up loss.

CR: complete response; PR: partial response; MR: minor response; NC: no change; PG: progression; GKS: gamma knife surgery; WBSRT: whole-brain and spinal cord radiotherapy; AFP: alpha fetoprotein; $\beta$-HCG: beta chorionic gonadotrophin.

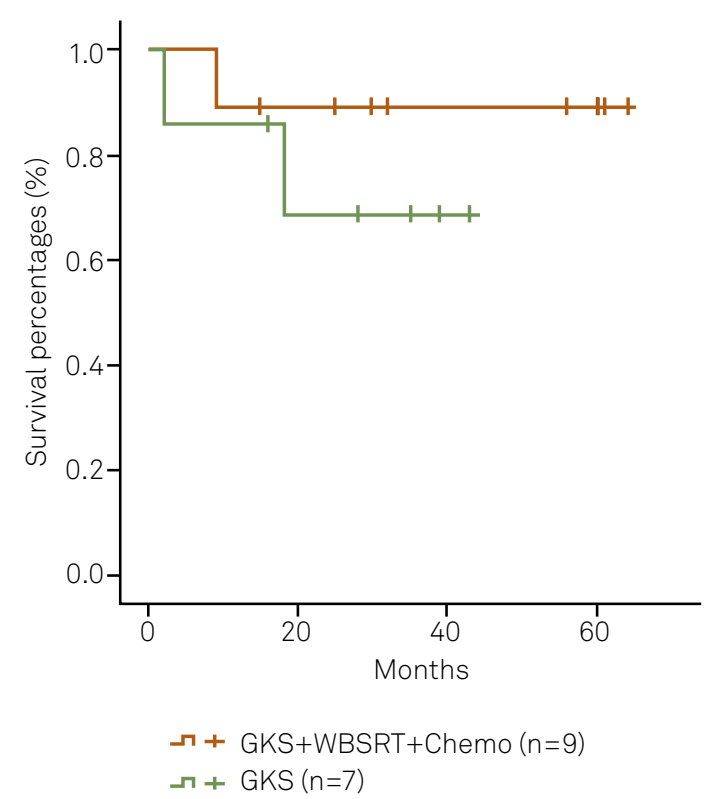

GKS: gamma knife surgery; Chemo: chemotherapy; WBSRT: whole-brain and spinal cord radiotherapy.

Figure 1. Kaplan-Meier curves demonstrating survival time for patients treated with GKS plus Chemo and WBSRT $(n=9)$ or GKS only $(n=7)$. One patient who was lost to follow-up was excluded. 


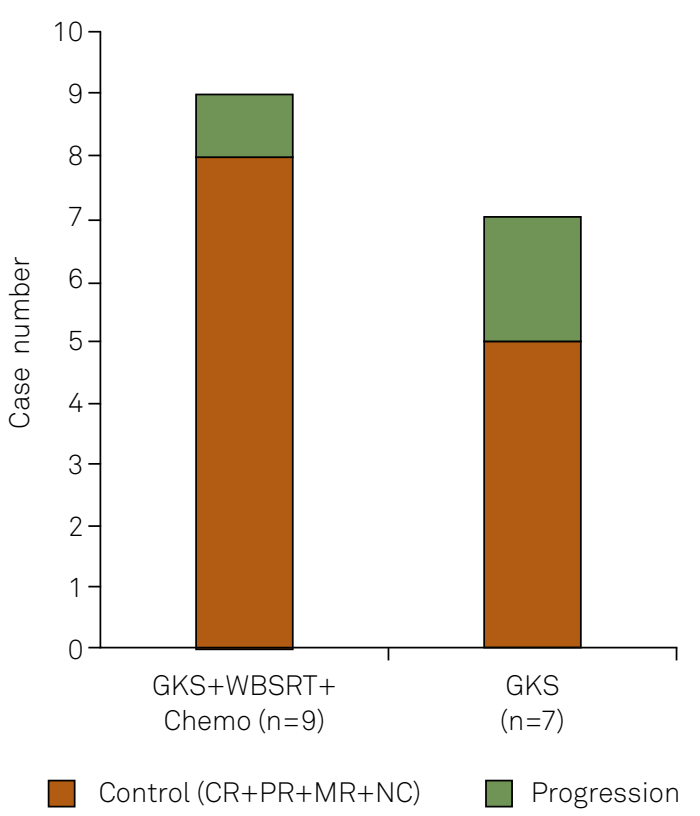

GKS: gamma knife surgery; Chemo: chemotherapy; WBSRT: whole-brain and spinal cord radiotherapy; CR: complete response; PR: partial response; MR: minor response; NC: no change.

Figure 2. Control rate of patients treated with GKS plus Chemo and WBSRT $(n=9)$ or GKS only $(n=7)$. One patient who was lost to follow-up was excluded.

radiosurgery with ventricular and spinal spread. The third died 18 months following multiple recurrences; however, the MRI of this patient taken 3 months after GKS revealed a satisfactory decrease in tumor size.

The mean KPS at 6 months after GKS (excluding those who died or were lost to follow-up) was 94.6, compared to 63.8 when they were first admitted to hospital. No obvious neurological deficits or complications, such as brain edema or cerebral radiation necrosis, were attributable to GKS.

\section{Selected cases}

\section{Case 1}

A 27-year-old man complained of a 1-month history of headache and vomiting. Cranial MRI revealed a lesion with enhancement in the pineal region (Figure 3). VPS was performed, followed by GKS with a marginal dose of 13 Gy and a 50\% isodose line. Four months later, the patient underwent WBSRT with a dose of 3600 cGy, as well as Chemo. Follow-up confirmed a CR for more than 56 months.

\section{Case 2}

An 18-year-old boy complained of headache that had lasted for 10 days. MRI showed an enhanced lesion in the pineal region (Figure 4). The patient only underwent GKS, and the tumor reduced 3 months later. However, a small enhanced lesion was still present on MRI 6 months after GKS, but did not show any obvious changes at later follow-up assessments.

\section{Case 3}

A 45-year-old man complained of headache for 15 days. MRI revealed an enhanced lesion in the pineal region (Figure 5A), and GKS was performed followed by WBSRT at a dose of 3420 cGy, as well as Chemo with temozolamide 3 months later. At 4 months after GKS there was a minor change in the lesion, with tumor seeding to the fourth ventricle (Figure 5B). The tumor showed PG at 7 months with ventricular and spinal spread (Figure $5 \mathrm{C}$ ), and the patient died 9 months after GKS.

\section{DISCUSSION}

Compared to conventional irradiation, GKS is a better treatment tool for PRT patients. It can greatly protect adjacent brain tissue while directing a high dose to the tumor. Kobayashi and colleagues ${ }^{19}$ reported on their use of stereotactic gamma radiosurgery for 30 pineal and related tumors, among which 3 cases without histological diagnosis were initially treated with GKS. A CR was obtained in 1 case and PRs in 2 during a mean follow-up period of 23.3 months. In the present research of 17 cases, 9 cases had a CR, and 3 cases obtained a PR over a mean follow-up period of 33.3 months. The total response rate was $75 \%$, and the control rate was $81.3 \%$. Thirteen patients $(81.3 \%)$ were alive at the end of follow-up. These outcomes were analogous to a previous report in which pathological diagnoses were proven ${ }^{19,20}$.

Good quality of life was also seen in the present patients. Many studies have reported that good outcomes were obtained with fewer complications, although more invasive diagnostic treatments were applied ${ }^{13,19-25}$. We recorded the KPS of patients at admission and 6 months after GKS (excluding those who died or were lost to follow-up). The mean KPS at the 6-month follow-up was 94.6, compared to the KPS of 63.8 when patients were first admitted to the hospital. We did not find any evidence of obvious neurological deficits or complications, such as brain edema or cerebral radiation necrosis. Most of our patients were able to return to school or their previous job 1-3 months after treatment.

One of the factors underlying outcome is the radiosensitive nature of some PRTs, such as germinomas, which have 5-year survival rates of roughly $90 \%$ with radiotherapy alone ${ }^{1}$. These tumors account for a higher rate of PRTs in Asia, and usually occur in males ${ }^{17}$. The male:female ratio in our patients was 15:2, which suggests that radiosensitive PRTs may have accounted for the majority of cases. According to this characteristic and preoperative imaging evaluations, we selected mid-range doses for GKS compared to previous studies ${ }^{20,23}$.

Another factor was the minimal invasiveness of GKS. Conventional radiation therapy for PRTs usually produces sequelae, such as cognitive deficits, endocrinopathies, secondary malignancies, growth arrest, and marrow suppression ${ }^{26}$. 

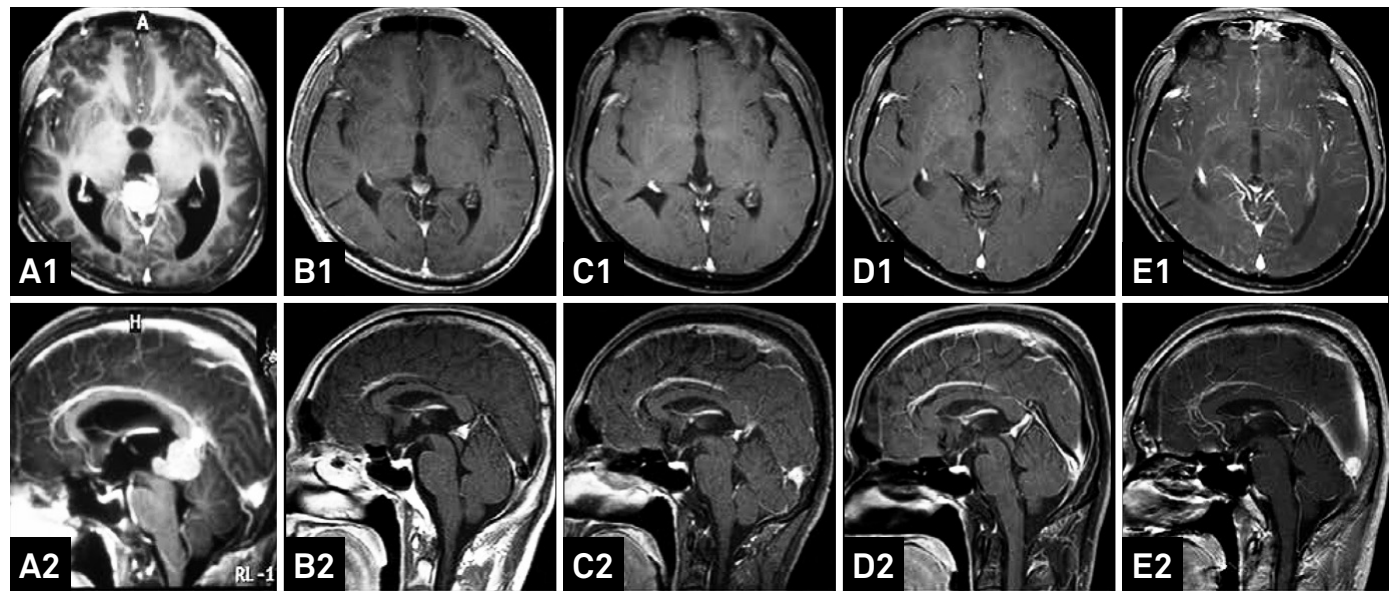

GKS: gamma knife surgery; Chemo: chemotherapy; WBSRT: whole-brain and spinal cord radiotherapy; CR: complete response; MRIs: magnetic resonance images;VPS: ventriculoperitoneal shunt.

Figure 3. Follow-up MRIs of a 27-year-old patient treated with VPS, GKS, Chemo, and WBSRT. A lesion with enhancement (A1, A2) was found in the pineal region before treatment and decreased 4 months later (B1, B2). MRIs at 23 months (C1, C2), 38 months (D1, D2), and 56 months (E1, E2) showed a CR.
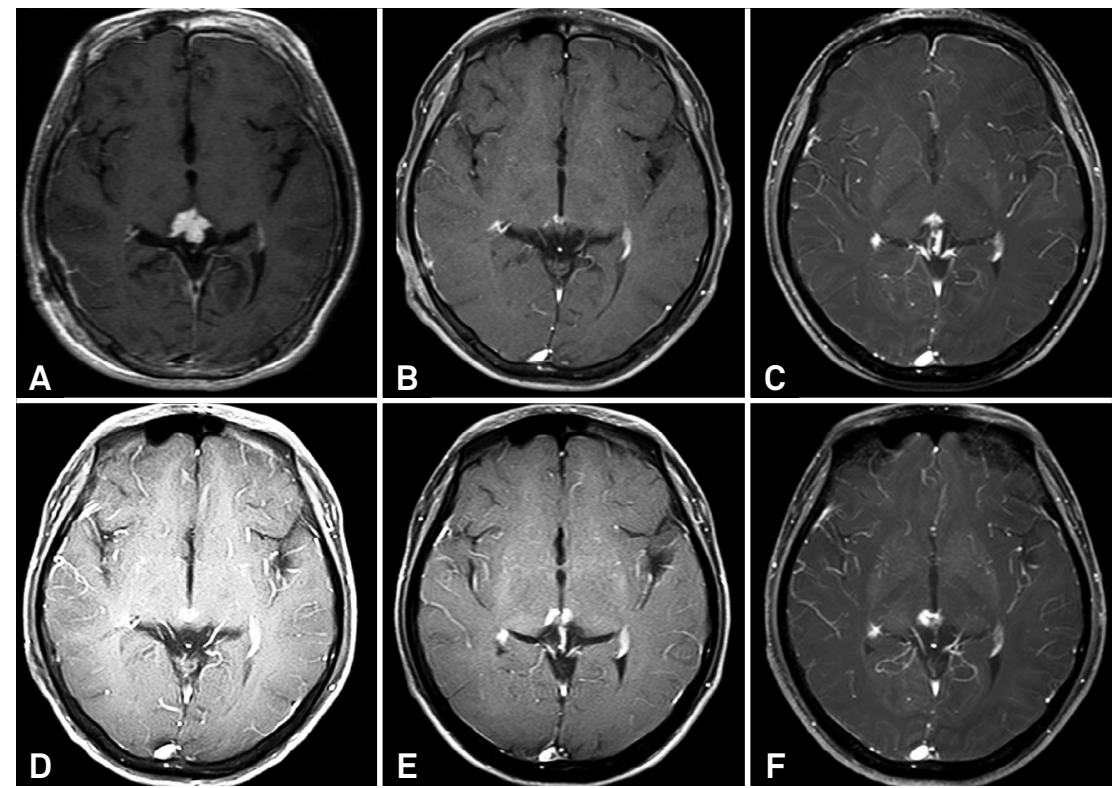

MRIs: magnetic resonance images; GKS: gamma knife surgery.

Figure 4. Follow-up MRIs of an 18-year-old male patient treated with GKS only. An enhanced lesion (A) was found in the pineal region and decreased 3 months after GKS (B). However, a small enhanced lesion was found at 6 months (C) and persisted at 12 months (D), 24 months (E), and 35 months (F).

The risk for these morbidities is particularly high in young children and in patients with a long life expectancy ${ }^{1}$. GKS can greatly protect adjacent brain tissue when delivering large single-fraction radiation doses to a focal area. In the published research on PRTs treated with GKS ${ }^{13,19-25}$, obvious neurological deficit and complications were not typically attributable to GKS. A similar result was also observed in our study.

Tumor markers, such as AFP and $\beta$-HCG, are useful prognostic factors, and all patients should undergo routine tests ${ }^{14}$. We found that CR was most likely to be obtained in patients with negative markers regardless of whether they were treated with GKS only or GKS followed by WBSRT and Chemo. Our findings indicate that patients with positive markers are more likely to have malignant tumors, and those with both negative AFP and $\beta$-HCG results may have the best outcomes following radiosurgery.

It is important to note that some PRTs have a certain rate of ventricular and spinal spreading. For example, $2-37 \%$ of germinomas have distant metastases after apparent local cures ${ }^{1}$. This problem cannot be solved by GKS 

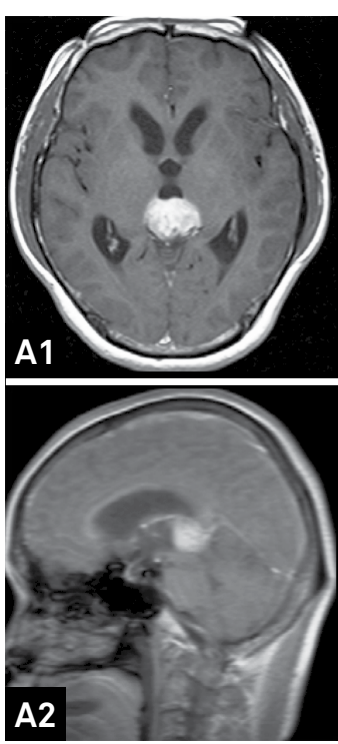
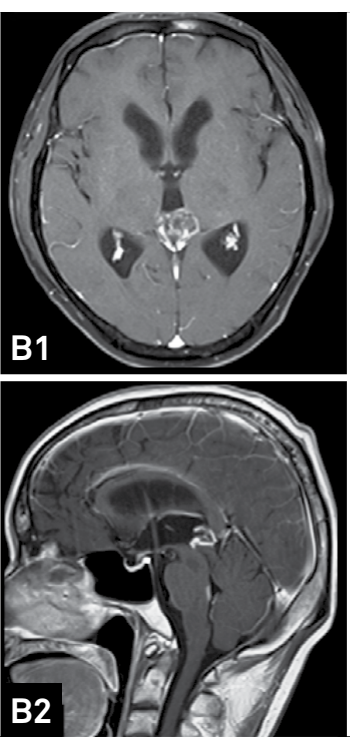
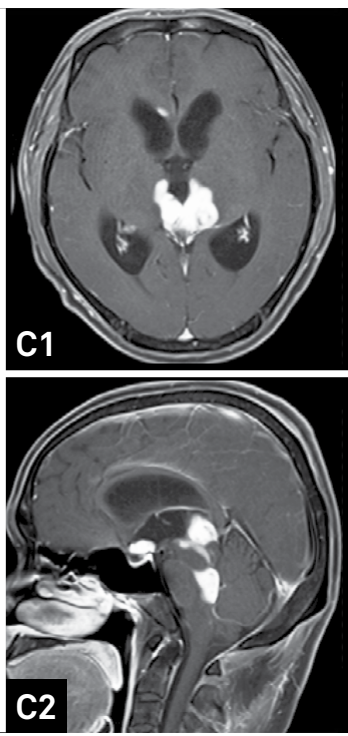

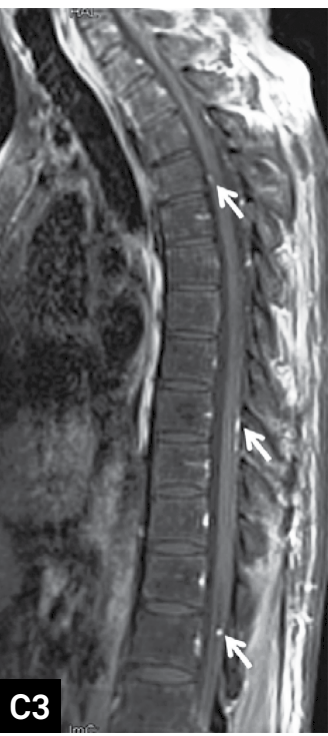

GKS: gamma knife surgery; Chemo: chemotherapy; MRIs: magnetic resonance images; WBSRT: whole-brain and spinal cord radiotherapy.

Figure 5. Follow-up MRIs of a 45-year-old male patient treated with GKS, Chemo, and WBSRT. An enhanced lesion (A1, A2) was found in the pineal region and slightly 4 months after treatment (B1, B2). MRIs taken at 7 months (C1-C3) revealed that the tumor had spread to the saddle area and fourth ventricle, as well as the spinal cord (C3, white arrow).

alone, as it treats a limited irradiation region. Hence, GKS followed by WBSRT and Chemo is theoretically the better choice for PRT patients with no or unclear pathological diagnoses. Endo and colleagues ${ }^{21}$ reported that combined radiotherapy using GKS is effective for pineal germinoma and reduces the cost of treatment by shortening hospitalization. Hasegawa and colleagues ${ }^{13}$ pointed out that multimodality therapy, including stereotactic radiosurgery, fractionated radiotherapy, and Chemo, is required for more aggressive pineal parenchymal tumors. One of our patients whose enhanced lesion disappeared at 3 months after GKS died of multiple recurrences at 18 months, which might be attributable to GKS monotherapy without adjunct WBSRT and chemotherapy. However, a difference in survival and control rates between GKS only and GKS followed by WBSRT plus Chemo was not observed in this retrospective study. This may be because of the small sample size. For further studies, it remains an open question whether every patient with a negative pathological diagnosis should routinely receive WBSRT and Chemo after initial GKS.

In conclusion, GKS may be an alternative strategy in a subset of PRT patients who have negative pathological diagnoses, and good quality of life can be obtained with a low risk of complications.

\section{References}

1. Blakeley JO, Grossman SA. Management of pineal region tumors. Curr Treat Options Oncol 2006;7:505-516.

2. Hirato J, Nakazato Y. Pathology of pineal region tumors. J Neurooncol 2001;54:239-249.

3. Fevre-Montange M, Vasiljevic A, Champier J, Jouvet A. Histopathology of tumors of the pineal region. Future Oncol 2010;6:791-809.

4. Konovalov AN, Pitskhelauri DI. Principles of treatment of the pineal region tumors. Surg Neurol 2003;59:250-268.

5. Kang JK, Jeun SS, Hong YK, et al. Experience with pineal region tumors. Childs Nerv Syst 1998;14:63-68.

6. Shin HJ, Cho BK, Jung HW, Wang KC. Pediatric pineal tumors: need for a direct surgical approach and complications of the occipital transtentorial approach. Childs Nerv Syst 1998;14:174-178.

7. Yamini B, Refai D, Rubin CM, Frim DM. Initial endoscopic management of pineal region tumors and associated hydrocephalus: clinical series and literature review.J Neurosurg 2004;100:437-441.
8. Pople IK, Athanasiou TC, Sandeman DR, Coakham HB. The role of endoscopic biopsy and third ventriculostomy in the management of pineal region tumours. Br J Neurosurg 2001;15:305-311.

9. Ferrer E, Santamarta D, Garcia-Fructuoso G, Caral L, Rumia J. Neuroendoscopic management of pineal region tumours. Acta Neurochir (Wien) 1997;139:12-21.

10. Radovanovic I, Dizdarevic K, de Tribolet N, Masic T, Muminagic S. Pineal region tumors--neurosurgical review. Med Arh 2009;63:171-173.

11. Edwards MS, Hudgins RJ, Wilson CB, Levin VA, Wara WM. Pineal region tumors in children.J Neurosurg 1988;68:689-697.

12. Field M, Witham TF, Flickinger JC, Kondziolka D, Lunsford LD. Comprehensive assessment of hemorrhage risks and outcomes after stereotactic brain biopsy. J Neurosurg 2001;94:545-551.

13. Hasegawa T, Kondziolka D, Hadjipanayis CG, Flickinger JC, Lunsford LD. The role of radiosurgery for the treatment of pineal parenchymal tumors. Neurosurgery 2002;51:880-889. 
14. Bruce JN, Ogden AT. Surgical strategies for treating patients with pineal region tumors. J Neurooncol 2004;69:221-236.

15. Choi JU, Kim DS, Chung SS, Kim TS. Treatment of germ cell tumors in the pineal region. Childs Nerv Syst 1998;14:41-48.

16. Kanamori M, Kumabe T, Tominaga T. Is histological diagnosis necessary to start treatment for germ cell tumours in the pineal region? J Clin Neurosci 2008;15:978-987.

17. Nomura K. Epidemiology of germ cell tumors in Asia of pineal region tumor. J Neurooncol 2001;54:211-217.

18. Shibui S, Nomura K. Statistical analysis of pineal tumors based on the data of Brain Tumor Registry of Japan. Prog Neurol Surg 2009;23:1-11.

19. Kobayashi T, Kida Y, Mori Y. Stereotactic gamma radiosurgery for pineal and related tumors. J Neurooncol 2001;54:301-309.

20. Amendola BE, Wolf A, Coy SR, Amendola MA, Eber D. Pineal tumors: analysis of treatment results in 20 patients. J Neurosurg 2005;102:S175-S179.

21. Endo H, Kumabe T, Jokura H, Tominaga $\mathrm{T}$. Stereotactic radiosurgery followed by whole ventricular irradiation for primary intracranial germinoma of the pineal region. Minim Invasive Neurosurg 2005;48:186-190

22. Lekovic GP, Gonzalez LF, Shetter AG, Porter RW, et al. Role of Gamma Knife surgery in the management of pineal region tumors. Neurosurg Focus 2007;23:E12.

23. Mori Y, Kobayashi T, Hasegawa T, Yoshida K, Kida Y. Stereotactic radiosurgery for pineal and related tumors. Prog Neurol Surg 2009;23:106-118.

24. Kano H, Niranjan A, Kondziolka D, Flickinger JC, Lunsford D. Role of stereotactic radiosurgery in the management of pineal parenchymal tumors. Prog Neurol Surg 2009;23:44-58.

25. Reyns N, Hayashi M, Chinot O, et al. The role of Gamma Knife radiosurgery in the treatment of pineal parenchymal tumours. Acta Neurochir (Wien) 2006;148:5-11.

26. Maity A, Shu HK, Janss A, et al. Craniospinal radiation in the treatment of biopsy-proven intracranial germinomas: twenty-five years' experience in a single center. Int $J$ Radiat Oncol Biol Phys 2004;58:1165-1170. 